\title{
VALLES, COFRADÍAS DE CLÉRIGOS Y SEÑORES EN EL ESTE DE LA PROVINCIA DE BURGOS (1383-1600)
}

\author{
POR \\ José Antonio Cuesta Nieto ${ }^{1}$ \\ Universidad de Burgos
}

\begin{abstract}
RESUMEN
En los valles que se abren a los pies de la Sierra de la Demanda se fundaron al final de la Edad Media una serie de cofradías que comprendían a los curas y beneficiados de todos los lugares de cada uno de estos valles. Hasta entonces los concejos de los pequeños lugares carecían de desarrollo jurisdiccional, pues, carentes de oficiales propios, dependían de los oficiales de las villas cabeza de jurisdicción y de sus señores; por eso entonces el clero parroquial encabezaba los concejos rurales. Entendemos que las cofradías de clérigos fueron el primer paso hacia el desarrollo institucional de entidades jurisdiccionales más amplias y que jugaron un cierto papel entre los lugares medievales y las villas y hermandades, integradas por uno o varios valles, posteriores.
\end{abstract}

PALABRAS CLAVE: Castilla la Vieja; clero; cofradías; señoríos; concejos.

\section{VALLEYS, CONFRATERNITIES OF CLERGYMEN AND LORDS IN THE EAST OF THE PROVINCE OF BURGOS (1383-1600)}

\begin{abstract}
In the valleys of the Sierra de la Demanda, several confraternities of clergymen were founded at the end of the Middle Ages. In the Late Middle Ages the Magnate - who became lords through the concept of Manorialism in villas that headed up the jurisdiction - gained power. Small localities, lacking their own officials, depended on these larger, leading jurisdictional villas and their lords - and thus the parochial clergyman led their councils. The confraternities of clergymen were the first step towards subsequent villas and brotherhoods, these being made up of one or several valleys and likewise being independent from the leading jurisdictional villas.
\end{abstract}

KEY WORDS: Castilla la Vieja; clergyman; confraternities; manorialism; councils.

Cómo CITAR ESTE ARTículo / CITATION: Cuesta Nieto, J. A. 2019. «Valles, cofradías de clérigos y señores en el este de la provincia de Burgos (1383-1600)». Hispania Sacra 71, 143: 103-111. https://doi.org/10.3989/hs.2019.007

$\begin{array}{ll}\text { Recibido/Received } & \text { 21-06-2016 } \\ \text { Aceptado/Accepted } & \text { 01-02-2017 }\end{array}$

\section{INTRODUCCIÓN}

Aunque suele dejarse constancia de la existencia de cofradías de clérigos, la historiografía sobre la misma es limitada, ${ }^{2}$ y, además, se centra más en el ámbito urbano, ${ }^{3}$ que

1 jacnieto@ubu.es/ORCIDiD: https://orcid.org/0000-0001-9304-2725

2 Un planteamiento general sobre las cofradías de clérigos en la Edad Media en Martín Martín 2004: 71-73.

3 Herrera Mesa 1978; Osorio Muñoz 1984; Diago Hernando 1997; Iturrate 1999; Vázquez Bertomeu 1999; Barreiro Mallón 2008. Un caso especial es la Hermandad de San Pedro fundada en la capilla de San Pedro Mártir del convento dominico de Nuestra Señora de Valcuerna de Logroño que integraba a los oficiales, familiares y ministros, clérigos y laicos, de todo el tribunal de la Inquisición de Logroño, aunque solo acudían a sus celebraciones los hermanos en un radio de cinco leguas en torno a la ciudad; Goicoechea 1951: 165-174. Se fundaron también en Toledo, Talavera de la Reina, Cuenca, Huete y en villas conquenses más pequeñas, como Moya, Uclés, Alcocer, Castillo de Garcimuñoz y, probablemente, Alarcón. Se constituyó una nada más conquistarse Alcaraz con la misión de defender los intereses comunes de los beneficiados, ordenar los actos litúrgicos en la villa y administrar las rentas que le pertenecían; Ayllón Gutiérrez 2015: 50-51 y 119-120; Aranda Pérez 2000. En la diócesis de Burgos existieron en la propia ciudad, Castrojeriz y Cerezo de Río Tirón, aunque poco sabemos de su desarrollo. 
en el rural, donde destacan los estudios de J. Iturriate sobre cofradías alavesas. ${ }^{4} \mathrm{~J}$. L. Martín considera que los clérigos se agrupaban en cofradías y hermandades «para mejor cumplir los fines de su estado, el culto divino y la atención a los fieles», aunque también para atender a "los intereses concretos» de su grupo frente a otros poderes y entidades. ${ }^{5}$

En la diócesis de Burgos el asociacionismo de los clérigos alcanzó bastante relevancia a lo largo del tiempo. De finales del siglo XIV a comienzos del XVI hemos documentado varias cofradías de clérigos que se localizaban en los valles de la Sierra de la Demanda, los Montes de Oca e inmediaciones. ${ }^{6}$ Las más antiguas son la cofradía de Santa
María de Vega del Valle de Valdelaguna y Monterrubio (1383), ${ }^{7}$ que comprendía los clérigos de nueve poblaciones (Barbadillo de Herreros, Bezares, Huerta de Abajo, Huerta de Arriba, Quintanilla de Urrilla, Riocavado de la Sierra, Tolbaños de Abajo, Tolbaños de Arriba y Monterrubio de la Demanda, que no pertenecía al valle), y, probablemente, la del Valle de San Vicente (Espinosa del Monte, Pradoluengo, San Clemente del Valle, San Vicente del Valle, Santa Cruz del Valle, Santa Olalla del Valle, Soto del Valle, Valmala y Villagalijo). ${ }^{8}$ La congregación o cofradía de San Martín del Valle de Piedrahita contaba con una regla de $1578,{ }^{9}$ que era una reelaboración de otra más antigua (1515), ${ }^{10}$ aunque la

MAPA

Las cofradías de clérigos de los valles del Este de la provincia de Burgos

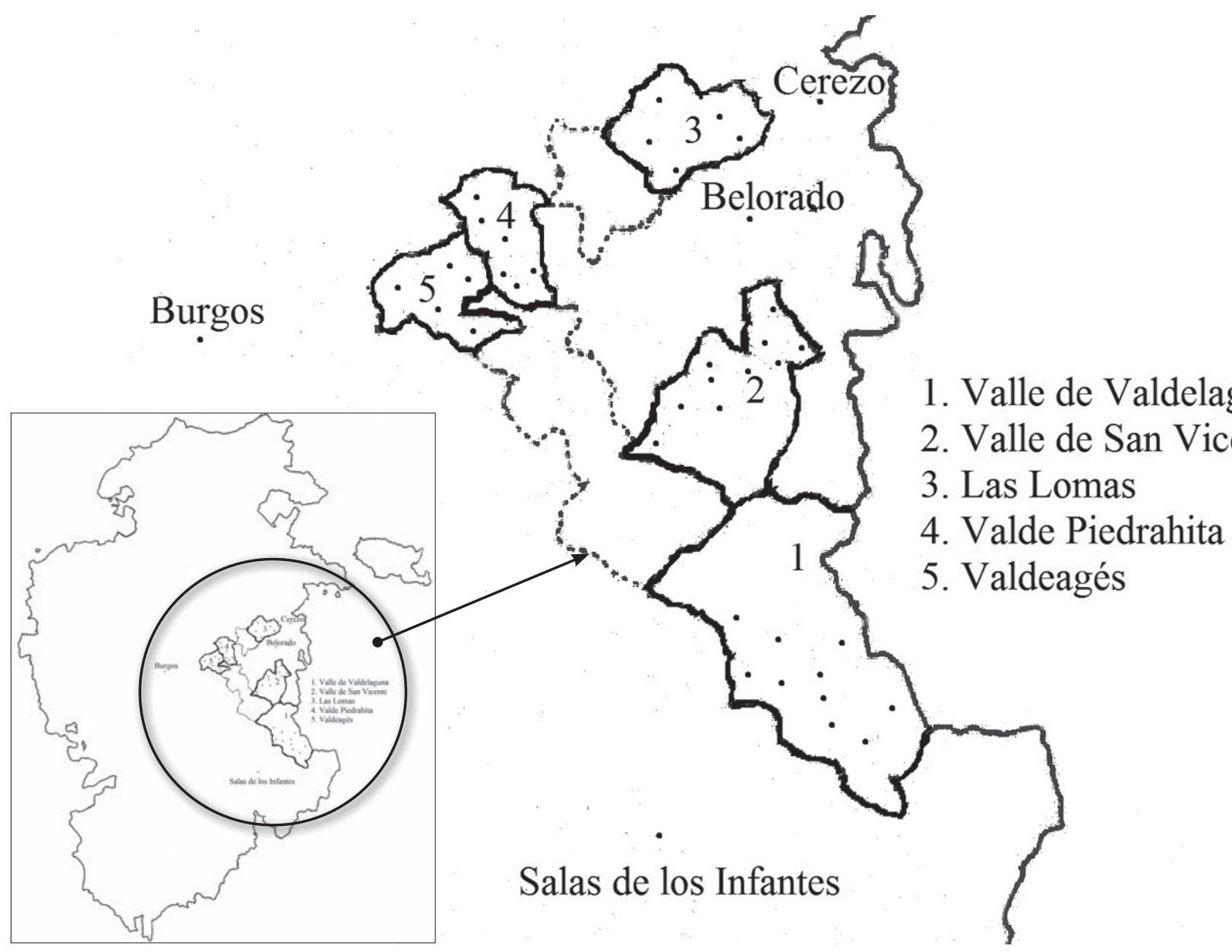

4 Moya Valgañón 1982; Iturrate 1995, 1997, 1998, 2000a, 2000b, 2001, 2002a, 2002b, 2003, 2004; Lozano Ruiz 2012.

5 Martín Rodríguez 1993: 138. La entrada de laicos en los cabildos de clérigos, no cofradías, la contempla bien como "protectores», es decir, como consecuencia de haber entregado bienes importantes para con su renta pagar misas y memorias perpetuas de aniversario, o bien bajo la fórmula de la «familiaritas» por la que tras entregar sus bienes entra en la comunidad eclesiástica como un miembro más. íbidem: 144-147.

6 Una descripción formal de la documentación, origen y características de las cofradías burgalesas en Vicario Santamaría 1996-2016.
7 Archivo Diocesano de Burgos [ADBu], Barbadillo de Herreros, Libro de la Cofradía (1421-1605).

8 Libros de la cofradía del cabildo del arciprestazgo del Val de San Vicente titulada de la Asunción de la Madre de Dios. Vicario Santamaría 1988: 721.

9 ADBu, Piedrahita de Juarros, Libros de la cofradía de San Martín de Valde Piedrahita.

10 Fue visitada y aprobada por los visitadores del arzobispado en $1582,1608,1624,1630,1635,1656,1662,1665,1668,1672$ y 1680. 
cofradía ya existía en $1475 ;{ }^{11}$ estaba formada por los clérigos de Piedrahita de Juarros, donde tenía su sede, y los de los lugares de Arraya, Quintanilla del Monte, Santa María del Invierno, Villaescusa la Solana y Villaescusa la Sombría, aunque, en sentido estricto, ni Arraya ni Quintanilla del Monte pertenecían al valle. Nombraba un abad, un prior y un procurador general. ${ }^{12}$ La cofradía de Valdeagés, algo posterior, reunía a los clérigos de otros cinco pueblos (Atapuerca, Agés, Santovenia de Oca, Barrios de Colina e Hiniestra) $)^{13}$ y a los de otros cinco, la confraternidad de los beneficiados de Quintanaloranco, Loranquillo, Bañuelos, Carrias y Castrillo o Castil de Carrias (Las Lomas). ${ }^{14}$

Alguna de estas cofradías tenía su sede en ermitas sitas en términos comuneros de varias poblaciones. Así, la de Santa María del Valle de Valdelaguna la tenía en la ermita del mismo nombre, sita en el término comunero de Patria, y la de San Martín del Valle de Piedrahita, en una ermita homónima sita en el referido lugar de Piedrahita de Juarros. Solo en estos casos las cofradías tenían un santo titular; en todos los demás su única denominación era la del valle en el que se ubicaban, lo que ya es de por sí un dato relevante.

En el norte de la provincia de Palencia estas cofradías fueron bastante numerosas. Como en Burgos, sus reglas, que suelen ser producto de la renovación de otras más antiguas, datan del siglo XVI o primera mitad del XVII y combinaban una función de asistencia mutua con su carácter estamental. Solían tener doce hermanos en recuerdo de los doce apóstoles, incluidos a veces dos legos, si bien estos carecían de voto. ${ }^{15}$

La concentración de este tipo de cofradías en el tiempo y en un ámbito geográfico determinado nos ha llevado a plantearnos su análisis más allá de su dimensión meramente religiosa y asistencial, que claramente tuvieron. Creemos que su desarrollo corre paralelo con el de la afirmación de la autonomía de los concejos locales frente a otros poderes externos a las comunidades rurales, es decir, señores y justicias de las villas cabeza de jurisdicción. ${ }^{16}$

11 En 1475 tenía unos ingresos de 65,5 fanegas de pan mediado; Casado Alonso 1987: 553.

12 1586, mayo, 7, y 1588, septiembre, 20. Villaescusa la Solana. Poderes para un pleito otorgados por Diego Ruiz de la Portilla, abad, Andrés Martínez, prior (y beneficiado en Arraya), Alonso Fernández de la Molina, procurador general, Diego Sáenz, Martín García, Juanes Pérez (cura de Arraya), Hernán Martínez (beneficiado en Arraya), Francisco Velázquez y Hernán Camino (beneficiado en Santa María del Invierno), cofrades. En 1588 se añade Juan Martínez. Archivo Histórico Provincial Burgos [AHPBu], Protocolos Notariales, leg. 1.133/3, fol. 63, y leg. 1.134, fol. 46 vo.

13 ADBu, Agés, Libros de la Cofradía de Valdeagés.

14 La única documentación que debe conservarse data de 1746, aunque no hemos dado con ella; Vicario Santamaría 1988: 304.

15 Lozano Ruiz 2012: 1171-1173. Un carácter parecido debió tener el "cabildo de Tresjuncos», documentada ya a principios del siglo XV e integrada por los beneficiados de Las Pedroñeras, El Pedernoso, Hontanaya, Las Mesas, El Hinojoso, Monreal, La Ossa, Puebla de Almenara, Robledillo de Záncara, Villaescusa de Haro y La Aceñuela, aldeas de la tierra de Alarcón, aunque no de la villa; Ayllón Gutiérrez 2015: 120.

16 Pudo tener rasgos similares la cofradía de San Martín de Revillarruz, que reunía a los curas de nueve localidades y, quizá, la de San Andrés de Quintanaortuño, que también tenía cofrades laicos, ambas en el centro de la diócesis de Burgos; Casado Alonso 1987: 527-528.

\section{LA SEÑORIALIZACIÓN DEL TERRITORIO}

Aunque toda esta comarca había sufrido una fuerte señorialización en la Plena Edad Media, la revolución Trastámara fue determinante en la configuración del mapa señorial, como en tantas otras partes, y transformó profundamente las relaciones de poder. La fuerza hegemónica fue la Casa de Velasco, pronto condes de Haro y, más adelante, condestables de Castilla y León y duques de Frías. Su asentamiento en el este de la actual provincia de Burgos se inició con el matrimonio de Fernán Sánchez de Velasco con Mayor de Castañeda, señora de la Casa de Salas de los Infantes, que aportó, entre otros bienes, derechos señoriales, compartidos con otros señores, en Barbadillo de Herreros, Bezares, Huerta de Arriba, Quintanilla de Urrilla, Riocavado de la Sierra, Tolbaños de Abajo y Tolbaños de Arriba. En 1371 Mayor de Castañeda, al crear el mayorazgo de la Casa de Salas para su hijo Pedro (I) Fernández de Velasco, incluía estos bienes. ${ }^{17}$ El sur de la sierra de la Demanda había pertenecido al antiguo alfoz de Lara, cuya jurisdicción se había fragmentado en varias circunscripciones de menores dimensiones. Entre ellas se encontraba el Valle de Valdelaguna, cuyo señorío, muy fragmentado entre distintos titulares, fue adquirido por los Velasco a lo largo del siglo XIV, mientras Monterrubio de la Demanda, que formó parte del valle de Valdecanales, fue donado en 1366 por Enrique II, con todo el señorío de Cameros, a Carlos Ramírez de Arellano, «El Noble». ${ }^{18}$

Al norte de la sierra de la Demanda sus dos hitos fundamentales fueron la obtención de los señoríos del Valle de San Vicente y de las villas de Cerezo de Río Tirón y Belorado, lo que permitió a los Velasco completar el dominio de otras villas y lugares dentro de sus jurisdicciones. En el Valle de San Vicente el señorío también estaba muy fragmentado en manos de numerosos titulares. Los Velasco fueron comprando todos los solares en un amplio intervalo de tiempo que se escalona entre 1371 y mediados del siglo XVI, salvo los de Lope de Rojas y sus sucesores en Santa Cruz del Valle, Soto y Garganchón, que acabaron formando otro estado señorial. ${ }^{19}$

Belorado fue donado por Juan II a Pedro (II) Fernández de Velasco, conde de Haro, en 1429, aunque no consolidó su dominio hasta $1445 .^{20}$ Esta villa, además de ser un hito en el camino de Santiago, era muy importante porque el alcaide de su castillo era merino en el Valle de San Vicente y porque sus alcaldes ordinarios ejercían la jurisdicción criminal sobre todas las villas y lugares de la merindad de Montes de Oca, ${ }^{21}$ llevando así el poder de los Velasco hasta el mismo alfoz de Burgos. Aunque Pedro Fernández de Velasco, I conde de Haro, fundó en 1458 un mayorazgo para su hijo segundo, Luis de Velasco, en el que incluyó la villa de Belorado con sus aldeas y el Valle de San Vicente, al ser de agnación rigurosa y no tener hijos varones, a su muerte sus bienes se reincorporaron al mayorazgo principal de la casa (1496). ${ }^{22}$

17 Moreno Ollero 2014: 231-232.

18 Cuesta Nieto 2007: 1.065-1.066; Moreno Ramírez de Arellano 1992: 23-24.

19 Cuesta Nieto 2007: 1.084-1.088.

20 Moreno Ollero 2014: 263-266.

21 En 6 de agosto de 1116 el aragonés Alfonso I el Batallador otorgó un fuero a Belorado que otorgaba a esta villa una gran autonomía jurisdiccional y le permitía elegir alcaldes; Martínez Díez 1982: 39-41 y 134-135.

22 Moreno Ollero 2014: 147-148; Franco Silva 2006: 127-128. 
Juan II donó a Pedro Fernández de Velasco el 7 de julio de 1445 la villa de Cerezo de Río Tirón, donación confirmada después de la batalla de Olmedo (15-VII-1447). ${ }^{23}$ Con esta villa unía sus dominios de la Demanda y Montes de Oca con los de la Bureba. Además, la villa de Cerezo ejercía la jurisdicción criminal sobre el Valle de San Vicente -la civil la ejercían sus propios alcaldes ordinarios $-{ }^{24}$ y la civil sobre las villas y lugares de la merindad de Montes de Oca, ${ }^{25}$ con lo que acababa por redondear su dominio sobre esta comarca.

La merindad de Montes de Oca estaba compuesta por cuatro villas con jurisdicción parcial y dieciocho lugares que pertenecían a distintos señores desde la Plena Edad Media, casi todos instituciones eclesiásticas. ${ }^{26}$ Entre estos señores destacan el monasterio de las Huelgas de Burgos, que lo era de Alcocero, Hiniestra, Loranquillo, Quintana de Loranco, Piedrahita de Juarros, Santa María del Invierno, Villamórico y el barrio de Santiago de Colina; ${ }^{27}$ el monasterio de San Juan de Ortega, ubicado en su territorio, de San Juan de Ortega, Quintanilla del Monte, Santovenia de Oca y barrio de Milanes; el monasterio de Santa María la Real de Nájera, de Agés; ${ }^{28}$ y la Orden de San Juan, de Atapuerca. Arraya de Oca, que estaba exenta de la merindad, era villa de señorío de la Casa de Velasco, que ponía alcalde mayor en ella con jurisdicción en lo civil, mientras en lo criminal pertenecía a la jurisdicción de Belorado. ${ }^{29}$

La posesión de la jurisdicción de la merindad de Montes de Oca como señor de Cerezo y de Belorado daba la oportunidad, no desaprovechada en otras ocasiones, para señorializar toda la jurisdicción ${ }^{30}$ y ese sería el intento, dada la debilidad de las instituciones monásticas, en el periodo bajomedieval.

D. Pedro (I) Fernández de Velasco tuvo tomados en encomienda 50 lugares de los monasterios de Silos, Arlanza, las Huelgas de Burgos, el Hospital del Rey y la abadía de Covarrubias, la mayor parte en la comarca de la Demanda y otros en sus inmediaciones; en las Cortes de Soria de 1380,

23 Crespo González 1981: 321 y 324; Moreno Ollero 2014: 272.

24 Cuesta Nieto 2007: 1.089-1.090.

25 Cerezo de Río Tirón contaba con un fuero otorgado por Alfonso VII, al parecer en 10 de enero de 1151, aunque la versión que se conoce de él es la de la confirmación hecha por Alfonso VIII en 1165 y redactada poco antes, la cual introduce la enumeración de las 134 aldeas con que se dotó su alfoz jurisdiccional; Martínez Díez 1982: $51-52$ y $154-155$.

26 Las villas eran Atapuerca, Barrios de Colina, compuesta por los barrios de Colina, Santiago y Milanes, Pineda de la Sierra y Villanasur; los lugares, Quintanilla del Monte, Agés, Alcocero, Cueva Cardiel, Hiniestra, Loranquillo, Piedrahita, Quintanaloranco, San Juan de Ortega, Santa María del Invierno, Santonvenia de Oca, Úzquiza, Villalmóndar, Villalbos, Villamórico, Villaescusa la Solana, Villaescusa la Sombría, Villasur de Herreros y Villorobe.

27 Lizoaín y García 1988: 144-189 (cuadro XIII); citado en Escrivá de Balaguer 1988: 47.

28 Alonso Martín y Palacio Sánchez-Izquierdo 1993: 152-155, 165 y 203-205.

29 Ni en el archivo de la Casa de Velasco ni en la bibliografía sobre la misma, que aquí se cita, hay referencia alguna a cómo esta población pasó a formar parte de su patrimonio.

30 Es lo que en 1603 acabó aconteciendo con Cascajares de la Sierra, Contreras, Villaespasa y Hortigüela, señoríos compartidos entre los Velasco y el monasterio de San Pedro de Arlanza en los que ejercía la jurisdicción ordinaria el gobernador de la Casa de Salas de los Infantes puesto por los Condestables de Castilla; Cuesta Nieto 2007: 1.048-1.053.
Juan I le condenó a su restitución. ${ }^{31}$ No obstante, en 1436, el comendador y freires del Hospital del Rey, con licencia de la abadesa del monasterio de las Huelgas de Burgos, otorgaron una carta de encomienda a favor de D. Pedro (II) Fernández de Velasco, I conde de Haro, a quien tomaron por protector y defensor suyo y de todos sus criados, vasallos, rentas y bienes. ${ }^{32}$ Por supuesto, el conde de Haro también tenía en encomienda a los vasallos del propio monasterio de las Huelgas. ${ }^{33}$ Así, obtuvo el dominio, aunque no el señorío, de buena parte de los lugares de la merindad de Montes de Oca. Hay que tener en cuenta que alguno de sus antepasados se había visto obligado a vender parte de su patrimonio al monasterio de Las Huelgas, caso de Fernán Sánchez de Velasco y su mujer Teresa Sánchez que en 1303 le vendieron sus solares y heredamientos de Alcocero, ${ }^{34}$ lo que aumentaba el interés por recomponer el patrimonio familiar, por otra parte, ya ampliamente acrecentado.

Parece que este sistema de encomiendas pudo mantenerse hasta la época de las Comunidades de Castilla en cuyo contexto se disolvió. La referencia a este respecto puede ser la villa serrana de Moncalvillo, señorío del Hospital del Rey, que en 1539 obtuvo sentencia definitiva de la Chancillería de Valladolid amparándola en el ejercicio de la jurisdicción por sus alcaldes ordinarios en contra de las pretensiones del Condestable, que pretendía ejercerla a través de su gobernador de la Casa de Salas de los Infantes. ${ }^{35}$

\section{VALLES Y CONGREGACIONES DE CLÉRIGOS}

Según los medievalistas, la red parroquial nació en el siglo XII. ${ }^{36}$ Desde entonces, la parroquia rural se estructura como «edificio de culto, comunidad de receptores de sacramentos y de futuros enterrados en un mismo templo, circunscripción territorial de administración eclesiástica». Además, "se presenta como la célula básica de relación social, generadora de unos vínculos de solidaridad vecinal, reforzados en no pocos casos por lazos de parentesco" que se manifiestan en la existencia de concejos parroquiales, institucionalizados desde comienzos del siglo XII; las reuniones se celebran en las iglesias, en ellas se acuerdan las acciones a seguir frente a los poderes superiores $y$ frente a otros concejos $y$, en ocasiones, se solicitan a la monarquía los privilegios de villazgo, otorgándose todos los documentos necesarios. ${ }^{37}$

Pero nuestros pueblos y sus parroquias se organizaron en «valles» superando el estricto marco local. El problema fundamental es determinar si es previa la organización en valles o no. La "comunidad de valle» es una forma de organización social del espacio de origen incierto y pleno desarrollo durante la Edad Media, presente siempre en comarcas de montaña; en la Península Ibérica lo está en la

31 Álvarez Borge 1996: 237-238.

32 Burgos, 2-XII-1436. Archivo Histórico de la Nobleza [AHNob], Frías, leg. 386/38.

33 «Cuenta de los mrs. del repartimiento que fue fecho a los vasallos del monasterio para pagar al Conde de Haro e son del año de mill e quatrozientos e treynta e quatro años». AHNob, Frías, leg. 388/2.

34 Estepa Díez 2003, vol. I: 381.

35 Cuesta Nieto 2007: 1.046-1.048.

36 Martín Martín 2004: 57.

37 Ruiz de la Peña Solar 1993: 57-59. 
cornisa cantábrica y el área pirenaica y también en zonas situadas más al sur, casi hasta el centro de la provincia de Burgos, conviviendo con otras formas de organización del espacio. Al pasar a formar parte de entidades superiores, solo algunos valles desarrollaron instituciones propias - villa y valle-, mientras otros se convirtieron en unidades administrativas, como alfoces, o distritos fiscales, llegando en otros casos a su práctica desaparición. ${ }^{38}$

En 1995 J. A. García de Cortázar explicaba que en La Rioja se intuía la existencia de "comunidades de valle», formadas por espacios comarcales situados en zonas de montaña de dedicación ganadera y forestal, del tipo de los existentes en las áreas cantábrica y pirenaica, y caracterizadas por ser «una unidad social de base territorial» con unas señas de identidad clara y quizá con una única jefatura social y política; aunque conservaron su identidad, el desarrollo de la agricultura fue disolviendo los lazos comunitarios del valle para sustituirlos por otros correspondientes a otros ámbitos de relación. En La Rioja hay noticias e indicios de la existencia de estas formaciones sociales, que están identificadas con la palabra "valle», asociadas a la idea de comunidad y de las que se nos trasmiten noticias sobre la posesión de espacios compartidos, sobre todo, ganaderos y forestales. No obstante, considera que solo el Valle de Ojacastro fue una comunidad de valle con seguridad; entre las otras, de las que solo se tienen indicios, queda el Valle de San Vicente, de lleno en territorio castellano. ${ }^{39}$ J. Escalona Monge, al estudiar el Alfoz de Lara, redefine el concepto de "valle» referido a la Cuenca del Duero para diferenciarlos de los grandes valles del Cantábrico; aquí se trataría de unidades más pequeñas, como villae romanas, que al desmembrarse habrían dado lugar solo a cuatro o cinco aldeas que repiten el mismo nombre, caso de Huerta de Arriba y Huerta de Abajo y Tolbaños de Arriba y Tolbaños de Abajo en el Valle de Valdelaguna. ${ }^{40}$ En esta última línea, D. Peterson, para explicar el origen del Valle de San Vicente, apuesta por la fragmentación de una villa romana, cuyo núcleo residencial estaba en San Vicente del Valle, en varias aldeas, mientras el concejo de valle no habría aparecido hasta la Baja Edad Media. ${ }^{41}$

Más confuso podría ser el caso de la merindad de Montes de Oca, donde los valles prácticamente han sido borrados; sin embargo, un documento de finales del siglo XV viene a aclararnos la cuestión al indicarnos que comprendía cinco valles - Montes de Oca, Valde Redoca, Valde Piedrahita, las Lomas y la Sierra-. ${ }^{42}$ Debemos tener en cuenta que Montes de Oca se identifica posteriormente como Valdeagés y la Sierra corresponde al valle del alto Arlanzón, entre Villasur de Herreros y Pineda de la Sierra, que evolucionó de forma un tanto diferenciada al resto de la merindad. Valdeagés, Valde Piedrahita y las Lomas contaron con sendas cofradías de clérigos.

Frente a las villas cabeza de jurisdicción y a los señores, los lugares carecían de un desarrollo jurisdiccional mínimo capaz de garantizar una autonomía que les sirviera para

\footnotetext{
38 Díez Herrera 2002.

39 García de Cortázar 1996 [2009].

40 Escalona Monge 2002: 225.

41 Peterson 2005: 168-174.

42 Archivo General de Simancas, Diversos de Castilla, leg. 41-31
} (2). defender sus propios intereses, pues hasta la segunda o tercera décadas del siglo XVI no documentamos los primeros oficiales concejiles. Estos serían los jueces, que tenían un escaso poder, no apareciendo hasta después de 1550 los primeros regidores y alcaldes pedáneos.

En esta etapa fueron las iglesias parroquiales y sus clérigos quienes dieron cauce institucional a estos concejos rurales. Son omnipresentes los documentos que nos hablan de la reunión de los concejos «debaxo de los portales de la iglesia», "en el portal de la iglesia», "delante de la iglesia» o "tras la iglesia» e igualmente los que presentan a los concejos encabezados por el cura, el cura y algún clérigo o un clérigo apareciendo a continuación una lista nominal de vecinos sin citarse oficial concejil alguno..$^{43}$

La formación de mancomunidades de aldeas en estos valles dio su primer paso mediante la constitución de cofradías por los clérigos de sus parroquias. El sentido político de algunas cofradías ha sido destacado en otros ámbitos donde sirvieron para la defensa de los intereses del común. ${ }^{44}$ Queda algo más. Es preciso verificar la confluencia de intereses entre el clero rural y los comunes de vecinos, más allá de su pertenencia a las familias de cada población, es decir, la confluencia en la defensa de los derechos eclesiásticos del clero local con la de los intereses concejiles y vecinales. ${ }^{45} \mathrm{~A}$ este respecto es muy revelador el pacto firmado por Juan González de Belorado con el concejo de Castil de Carrias, "clérigos y legos", por el que, a cambio de que sean sus vasallos y de "que subades luego a poblar en aquella heredad que yo he», no solo se obliga a respetar a los vecinos una serie de fueros, que se pactan, sino también sus derechos a los clérigos del lugar dando a entender que solo se les respetaban en los lugares de realengo, pero no en los señoríos. ${ }^{46}$ De este modo, la defensa de sus derechos frente a los señores unió a clérigos y vecinos.

El Valle de Valdelaguna tenía su centro político en el término de Vega o Patria, comunero de cuatro lugares del valle (Huerta de Abajo, Huerta de Arriba, Tolbaños de Abajo y Tolbaños de Arriba). Celebraba sus Ayuntamientos y juntas en la ermita de Nuestra Señora de Vega, que era también la

43 1488, mayo, 19-22. Poderes otorgados por Atapuerca, Agés, Santovenia de Oca, Hiniestra, Villaescusa de la Sombría, Quintanilla del Monte, Los Barrios de Colina y Villamórico. Archivo de la Real Chancillería de Valladolid, Pergaminos, leg. 2-1.

44 Es el caso de la cofradía del Cuerpo de Dios, que agrupaba a los vecinos del barrio de La Puebla de Palencia y que a mediados del siglo XV sirvió a los pecheros para luchar por una mayor participación en el gobierno de la ciudad; Esteban Recio 2015: 479 y ss. En términos generales en Sabe Andreu 2000: 20.

45 En la segunda mitad del siglo XV el clero de la villa burgalesa de Oña procede de los distintos tipos de familias de la localidad. A diferencia de las parroquias que aquí consideramos, la de Oña era una parroquia rica y algunos de sus clérigos, que solían pertenecer a familias de hacendados locales, pudieron alcanzar una mayor cualificación profesional -escribanos, notarios... - y promocionar dentro de la Iglesia, lo que tuvo como consecuencia que la parroquia «dejó de ser algo propio y representativo de las inquietudes e intereses de los vecinos, para pasar a ser un nuevo poder local, que adoptó e imitó comportamientos propios de los grupos privilegiados» (Ruiz Gómez 1990: 289-292).

461326 (era de 1364), noviembre, 15. Castil de Carrias. «E otrosý que a los clérigos del dicho lugar les sea guardado todo su derecho e todo su estado e toda su honra asý commo son en otras villas e lugares que son en el sennorío de nuestro sennor el rey do mejor e más conplidamente es vsado e acostumbrado». Inserto en AChVa, Registro de Ejecutorias, leg. 368/33. 
sede de la cofradía de Santa María del Valle de Valdelaguna y Monterrubio, y aquí se reunía también la cuadrilla mesteña de San Pedro de la Vega, de importancia fundamental para su economía. Se estableció que en honor de los doce apóstoles estuviera integrada por doce cofrades que fueran clérigos de los nueve pueblos del valle y de Monterrubio, pero, como algunos eran muy pequeños y podían no tener cura que residiera en su iglesia, se dispuso que lo pudiera sustituir un lego, norma con la que se trataba de mantener la representación de todos los pueblos del valle. ${ }^{47}$

En fin, iglesias y clérigos aportaban una ventaja a los concejos rurales, pues el fuero eclesiástico les situaba al margen de la capacidad de acción de los señores y sus justicias. Por esta razón no solo se celebraban las reuniones concejiles dentro del territorio de las parroquias, sino que los archivos concejiles estuvieron guardados en muchos casos en un arca dentro de las iglesias. ${ }^{48} \mathrm{Y}$ aún más, hay casos en que los clérigos locales son los que actúan en los pleitos antiseñoriales como procuradores de sus concejos. ${ }^{49}$ Conscientes de este papel, los señores trataron de controlar al clero rural..$^{50}$

\section{RENTAS Y MEMORIAS PERPETUAS: LA REPRESENTATIVIDAD SOCIAL DE LAS COFRADÍAS}

Quizá un medio para medir el grado de representatividad alcanzada por estas cofradías de clérigos sea el de las fundaciones de memorias perpetuas de aniversario y las donaciones de heredades que recibieron, si bien parecen proceder de las donaciones y mandas efectuadas por los propios clérigos. ${ }^{51}$ Las cofradías del Valle de San Vicente y de Valdeagés tenían unas rentas similares, mientras la cofradía de San Martín de Valde Piedrahita las triplicaba. Por contra, la cofradía de Santa María de Valdelaguna y Monterrubio y la congregación de clérigos de Bañuelos, Carrias, Castil de Carrias, Quintanaloranco y Loranquillo no tenían ninguna propiedad ni renta fija.

La cofradía del Valle de San Vicente a mediados del siglo XVIII tenía unas modestas rentas procedentes de la celebración de 68 memorias perpetuas por las que percibía 443 reales y 29 maravedís, ${ }^{52}$ que completaba con una tierra

47 1383. Regla de la cofradía de clérigos de Santa María de Vega y los doce apóstoles de Valdelaguna y Monterrubio. Publicada en Camarero Camarero y Cuesta Nieto 2017: 213-217.

48 Es el caso de Santo Domingo de Silos, Lara, Neila, entre otras villas, dentro de la comarca de La Demanda. También el de la Hermandad de Montes de Oca, cuyo archivo se conserva incorporado a su archivo parroquial, si bien en él no hemos hallado documentación anterior a 1700 .

49 Así lo hemos documentado en Barbadillo del Mercado en 1527 y 1528; Cuesta Nieto 2007: 1.007.

50 Diego López Pacheco, marqués de Villena, ejerció una efectiva autoridad sobre el clero de sus señoríos, sustituyendo en ocasiones a la autoridad religiosa a la hora de dar disposiciones en materia eclesiástica. Así, no es extraño que algunos clérigos se implicaran directamente en las luchas de bandos; Ayllón Gutiérrez 2015: 311 y 314-315.

51 Las cofradías y congregaciones de clérigos fundadas en la diócesis después de 1600 carecieron de patrimonios y rentas; Cuesta Nieto 2015.

52 Una memoria en Espinosa del Monte (4 reales), 10 en Pradoluengo (67 reales y 8 maravedís), 11 en San Clemente del Valle (62 reales y 11 maravedís), 12 en San Vicente del Valle (75 reales y 19 maravedís), 5 en Santa Cruz del Valle ( 5 celemines de trigo y 3 reales), 12 en Santa Olalla del Valle (111,5 reales), 2 en Soto del Valle (5,5 reales), 5 en Valmala (10,25 celemines de trigo y 3 reales) y 10 en Villagalijo (67 en Espinosa del Monte ( 2 celemines de sembradura) y 6 pequeños censos contra varios vecinos de Fresneda de la Sierra (28 reales de intereses).

La cofradía de Valdeagés percibía 90 celemines de pan mediado, trigo y cebada, que valían 231 reales y 14 maravedís, por el arrendamiento de 37 heredades (19 fanegas 9 celemines de sembradura) y 145 reales y 27 maravedís por la celebración de 13 memorias perpetuas. ${ }^{53}$ Además, en 1753 tenía un censo al quitar de 7 ducados de principal y 2 reales y 16 maravedís de intereses contra Tomás de Temiño, vecino de Atapuerca, y otro de 483,5 reales de principal y 14,5 reales de intereses contra Miguel Sáenz Colina, vecino de Hiniestra, sobre hipotecas en Barrios. En total, obtenía 393 reales y 30 maravedís.

La cofradía de San Martín de Valde Piedrahita era sin duda la que tenía unas rentas más amplias, pues suman 1.525 reales y 33,5 maravedís en 1753 . Contaba con una serie de bienes raíces extendidos por todos los pueblos del valle; contamos con un apeo de 1717, en el que se diferencian las tierras cedidas a censo de las dadas en arrendamientos cortos, y con las informaciones del Catastro de Ensenada, en el que solo aparecen tierras en arrendamiento. En 1717 se apean 46 tierras cedidas en arrendamientos cortos (36 fanegas) y 103 cedidas a censo perpetuo (99 fanegas y 9 celemines), lo que suma 149 tierras y 135 fanegas y 9 celemines de sembradura. ${ }^{54}$ En 1753 son 173 heredades que hacen 156 fanegas y 7,5 celemines de sembradura y rentan 60 fanegas y 7,5 celemines de trigo y 12,5 celemines de cebada, cuyo valor era de 983 reales y 23,5 maravedís. ${ }^{55}$

Apenas había memoria del origen de estas propiedades, salvo de los bienes cedidos a censo por el licenciado D. Simón de Molina por dos vidas, la suya y la de su sobrino Diego de Molina, y que en 1713 habían cedido a la cofradía Miguelo de Rodrigo y María Martínez, que él heredó de su

reales y 18 maravedís). Archivo de la Diputación Provincial de Burgos [ADPBu], Catastro de Ensenada. Se advierte que, aunque los datos a este respecto son tardíos, todo parece indicar que las propiedades y rentas de estas cofradías se formaron en su época fundacional.

53 Las heredades que tenía arrendadas eran 32 en Agés (16 fanegas de sembradura) por 58 celemines de pan mediado, una en Atapuerca ( 1 fanega 9 celemines) por 6 celemines de pan, una en Los Barrios de Colina ( 10 celemines) por 6 celemines de pan y 3 en Hiniestra ( 1 fanega 2 celemines), que estaba sin arrendar. Las memorias perpetuas que celebraba eran 8 en Agés (56,25 celemines de trigo), una en Atapuerca (6 celemines de trigo), 3 en Los Barrios de Colina (29 celemines de trigo y 15 reales) y una en Hiniestra (10 celemines de trigo). ADPBu, Catastro de Ensenada.

54 1717. En arrendamientos cortos estaban cedidas 44 tierras en Arraya (34 fanegas) y 2 en Villaescusa de la Sombría ( 2 fanegas) y a censo perpetuo 2 tierras en Arraya ( 2 fanegas), 25 en Piedrahita de Juarros (19 fanegas 2 celemines), 13 en Santa María del Invierno (13 fanegas 2 celemines), 15 en Villaescusa de la Solana (9 fanegas 8 celemines) y 33 en Villaescusa de la Sombría ( 27 fanegas 7 celemines). «Demarcazión y apeo de toda la hazienda raíz que pertenece al cauildo de San Martín del Valle de Valdepiedrahita en los términos de las villas de Arraya, Villaescusa de la Sombría, Villaescusa de la Solana y la de Santa María del Ybierno»; ADBu, Piedrahita de Juarros.

55 Figuran 69 tierras en Arraya (46 fanegas 11,5 celemines de sembradura) que rentaban 264 celemines de trigo, 26 tierras en Piedrahita de Juarros (31,5 fanegas) que rentaban 177 celemines de trigo, 33 tierras en Santa María del Invierno (48 fanegas 2 celemines) que rentaban 164 celemines de trigo, 14 tierras en Villaescusa de la Solana ( 9 fanegas) que rentaban 25 celemines de pan mediado, trigo y cebada, y 31 en Villaescusa de la Sombría ( 21 fanegas) que rentaban 110 celemines de trigo; ADPBu, Catastro de Ensenada. 
padre Pedro Martínez de Ungo. ${ }^{56}$ Por otro lado, algunas propiedades debieron perderse. En 1653 los hermanos de la cofradía emprendieron un pleito en la Audiencia Arzobispal de Burgos contra la fábrica de Arraya por el cobro de 25 celemines de trigo "por ciertas heredades y vienes raýces que toca a dicha yglesia y a pagado de tiempo ynmemorial a esta parte y agora se sustray a pagarlos $॥ ;{ }^{57}$ estas propiedades no aparecen en los apeos que manejamos.

El segundo capítulo de rentas de esta cofradía eran las memorias perpetuas de aniversario celebradas en las cinco parroquias del valle. En 1753 celebraba un total de 69 memorias por las que percibía 33 fanegas y 7 celemines de trigo y 6 celemines de cebada, por lo que resultan unos 6 celemines por memoria de media; ${ }^{58}$ valían 542 reales y 10 maravedís. En 1800 se celebraban 58 misas, 13 en Arraya, 11 en Villaescusa la Solana, 9 en Villaescusa la Sombría, 10 en Piedrahita y 15 en Santa María del Invierno, ${ }^{59}$ lo que supone la pérdida de algunas de ellas, seguramente por reducción por ser su estipendio muy corto; considerados los mismos 6 celemines por memoria, generaban 29 fanegas de trigo. Sin embargo, en este año de 1800 se decía que «antiguamente» (1476) los clérigos de la cofradía celebraban 153 misas cantadas y rezadas a razón de 6 celemines de trigo por cada una, lo que habría supuesto 76,5 fanegas de trigo..$^{60}$

En lo que respecta a las cargas de la cofradía, contamos con lo anotado en Arraya en el Catastro de Ensenada, que habría que multiplicar por cinco, y una referencia de 1800. Ambas fuentes coinciden en el pago de 5 fanegas de trigo "por razón de oblación, cera y ropas» a las fábricas de las iglesias del valle, de modo que correspondía a 12 celemines a cada iglesia, pero no coinciden en las demás partidas. En 1753 sumaban todas las cargas 506 reales y 24 maravedís tasada la fanega de trigo a 18 reales. ${ }^{61}$

\section{VILLAS Y HERMANDADES}

Todo este conjunto de lugares tuvo una evolución diferenciada, aunque siempre orientada a la afirmación de su autonomía jurisdiccional frente a las villas cabeza de jurisdicción y a los señores.

Los lugares y villas de la jurisdicción de Cerezo se sirvieron de la Santa Hermandad creada por los Reyes

56 1713, febrero, 21. Burgos. Ante Joseph Martínez de Huidobro, escribano de su número.

57 1653, diciembre, 6. Poder para poner demanda otorgado por el bachiller José Delgado, prior de la cofradía y cura beneficiado en Santa María del Invierno, el Ldo. Andrés Mínguez, cura beneficiado en Piedrahita, el Ldo. Lucas Pascual Zorrilla, notario de la Inquisición y cura beneficiado en Santa María del Invierno, el bachiller Andrés Delgado, cura beneficiado en Villaescusa la Sombría, y el Ldo. Mateo Moreno, cura beneficiado en Santa María del Invierno; AHPBu, Protocolos Notariales, leg. 1.143/1, fol. 274 r. y vo.

58 Eran 15 memorias en Arraya ( 82,5 celemines de trigo), una en Fresno de Rodilla ( 3 reales y 4 maravedís), 8 en Piedrahita de Juarros (67,25 celemines de trigo), 24 en Santa María del Invierno (133,75 celemines de trigo), 13 en Villaescusa de la Solana (65 celemines de trigo) y 9 en Villaescusa de la Sombría (55,5 celemines de trigo y 6 celemines de cebada); ADPBu, Catastro de Ensenada.

59 ADBu, Piedrahita de Juarros. Libro de la regla, últimas páginas.

60 Casado Alonso 1987: 553.

61 En 1753 se pagarían también 171 reales y 16 maravedís de subsidio, 200 reales dados de limosna a los pobres el día de san Martín y 135 reales para comprar cera para sus celebraciones.
Católicos en 1476 para dotarse de un marco de autonomía. Hay que tener en cuenta que, a diferencia de la jurisdicción ordinaria, en este ámbito las villas cabeza de jurisdicción constituían una circunscripción y nombraban sus propios alcaldes y cuadrilleros y las localidades de su jurisdicción formaban otra que nombraba a los suyos. Así nació la Hermandad de Montes de Oca y Val de Redoca, integrada por todas las villas y lugares de la jurisdicción de Cerezo, que fijó su sede en Quintanilla del Monte, junto al monasterio de San Juan de Ortega, centro religioso de toda la jurisdicción. No tenemos noticia de ella hasta principios del siglo XVI.

El Valle de San Vicente estaba constituido en concejo con una jurisdicción muy limitada desde la Plena Edad Media. ${ }^{62}$ Pronto chocó con la villa de Cerezo y se plantearon los correspondientes pleitos en la Chancillería de Valladolid. Para resolverlos en 1548 se firmó un concierto a instancia del condestable de Castilla, señor de unos y otros, que designó a su alcalde mayor, el bachiller Leçiñana, para que actuara en su nombre. ${ }^{63}$ Básicamente, se acuerda reducir los derechos de los oficiales de justicia de Cerezo hasta cantidades de poca importancia, pero sin suprimirlos, reconociendo así la propiedad de la jurisdicción a la villa de Cerezo; ${ }^{64}$ en cambio, los derechos señoriales, que pagaban los nueve lugares del valle - nueve tocinos de 25 libras - y que percibía el alcaide de esa villa en nombre del Condestable, se mantienen, pese al interés del valle por suprimirlos. En fin, se establece que en un plazo de quince días se otorgue escritura de este acuerdo y se presente al condestable para que la ratifique -y si fuere preciso a la Chancillería de Valladolid-, lo que es un reconocimiento explícito de que el señorío y la jurisdicción pertenecen al condestable tanto en el Valle de San Vicente, como en Cerezo. ${ }^{65}$

El Valle de Valdelaguna reaccionó más tardíamente frente a la presión señorializadora de los Velasco y como consecuencia de la victoria en los pleitos que siguieron las Cinco Villas y Valdecanales con el conde de Aguilar. ${ }^{66}$ En

62 Cuesta Nieto 2007: 1.088-1.090; Peterson 2005: 171-173.

63 El concierto se hizo en Villambistia el 8-III-1548, actuando como procuradores de Cerezo el licenciado Bonal, corregidor, Diego de Caviedes, alcaide, Martín Hernández Pardo, procurador, y Antón Díez, escribano del concejo, y como procuradores del Valle de San Vicente el licenciado Bernardino de Salazar, letrado del valle, Pedro Gómez y Pedro Despinosa, alcaldes, y Francisco Martínez Tornero, procurador. El Condestable dio licencia para que ambas partes ratificaran el concierto (Casalarreina, 12-IV-1548), que efectivamente ratificó primero el Valle de San Vicente (Pradoluengo, Junta de Ordunte, 8-VII-1548) y después la villa de Cerezo (Cerezo, 6-XI-1548), en ambos casos ante Juan Díaz de Leyba, escribano de Cerezo. Finalmente, el Condestable de Castilla aprobó todo lo realizado (Herramelluri, 30-IV-1550); AHNob, Frías, leg. 392, docs. 7 y 8 .

64 En materia de derechos jurisdiccionales, se acuerda que los alcaldes de Cerezo lleven de los regidores y jurados del valle 60 maravedís cuando cumplieren sus mandamientos en vez de 600 que entonces llevaban; que el merino de Cerezo lleve un $20 \%$ en vez de un $10 \%$ de las ejecuciones que fuere a hacer "por vía de remiso»; que estas ejecuciones por vía de remiso no las haga el merino en el ganado de los vecinos sino primero "en el almaje de todo el concejo» y solo si no fuere suficiente en el ganado de los vecinos; que cuando la justicia, el escribano, sus criados y cabalgaduras hicieren la visita del valle lleven un yantar como hasta ahora y en vez de los 60 maravedís que daba cada lugar 40 maravedís.

65 Cuesta Nieto 2007: 1.090-1.091.

66 El grueso de los pleitos estaba concluido en 1529, aunque todavía se siguió otro pleito sobre la pretensión del conde de Aguilar de introducir un gran número de cabezas de ganado en los pastos de las 
1554 inició un pleito que culminó en 1563 en que el Consejo de Castilla dictó sentencia en grado de segunda suplicación anulando todas las pretensiones en materia jurisdiccional de los condestables y, por tanto, confirmando al valle como villa realenga con jurisdicción plena. ${ }^{67}$

Las cofradías de clérigos se transformaron también al hilo de estos cambios y de las reformas impulsadas por el Concilio de Trento. Las cofradías reformaron sus reglas o las añadieron nuevos capítulos para adaptarse a los nuevos tiempos. A partir del reinado de los Reyes Católicos las cofradías políticas perdieron su sentido y desaparecieron ${ }^{68}$ o, como en este caso, se transformaron.

\section{CONCLUSIONES}

En los valles de la sierra de la Demanda y de Montes de Oca estaban asentados una serie de pequeños pueblos en los que la señorialización ya era muy intensa en la Plena Edad Media. Sin embargo, el asentamiento de la Casa de Velasco en esta comarca supuso una intensificación del poder señorial, pues, a partir de la instauración de los Trastámara, obtuvieron la concesión de la jurisdicción realenga que venían ejerciendo los alcaldes de las villas cabeza de jurisdicción. En este sentido, la donación de las villas de Belorado y Cerezo de Río Tirón al conde de Haro resultó fundamental para asentar su dominio sobre el Valle de San Vicente y la merindad de Montes de Oca. Solo el que la mayor parte de los abadengos pertenecieran al monasterio de las Huelgas y alguno, al Hospital del Rey de Burgos, casas que eran de fundación real, les salvó de ser convertidos en señoríos solariegos de los Velasco.

La intensificación del dominio señorial parece que favoreció la cooperación entre las aldeas próximas que así reforzaron su agrupación en valles sin por eso perder su propio término, ni su propio concejo local. Hasta las primeras décadas del siglo XVI la vida de los concejos estuvo superpuesta a su estructura parroquial; los concejos se reunían ante las iglesias, en ellas se guardaban sus reducidos archivos y sus clérigos los encabezaban y solían actuar como sus representantes ante otros concejos -al firmar concordias sobre pastos y términos, por ejemplo$y$ en otras instancias. El que en varios de estos valles se fundaron cofradías de clérigos que agruparan a todo el clero parroquial de todas sus poblaciones solo hemos podido interpretarlo como un proceso natural fruto de la evolución de sus concejos que también caminaban hacia su agrupación y que reforzaba desde lo eclesiástico y lo religioso este proceso.

Donde la hidalguía rural era lo suficiente numerosa engrosó las clientelas señoriales, por lo que para los nobles fue mucho más fácil obtener sus objetivos, pues actuaba desde el propio tejido social de estas comunidades rurales. Así, en los lugares de la Jurisdicción de Salas de los Infantes el poder señorial se asentó contando con la colaboración de la pequeña nobleza local agrupada en la Cofradía de hidalgos de Nuestra Señora de las Candelas de Villaespasa,

Cinco Villas y Valdecanales que se sentenció por el Consejo de Castilla a favor de las villas en diciembre de 1552 (Sainz Ochoa 2014: 237-238).

67 Cuesta Nieto 2007: 1.068-1.069

68 Sabe Andreu 2000: 20. cuya sede realmente estaba en la ermita de este nombre que radicaba en término de Jaramillo Quemado; ${ }^{69}$ aquí el clero solía pertenecer a las mismas familias de hidalgos y Villaespasa y los abadengos próximos, pertenecientes al monasterio de San Pedro de Arlanza, acabaron formando parte de los señoríos de la Casa de Salas, uno más de los de la Casa de Velasco.

Este debió ser el caso de Castilla Vieja, comarca dividida también en valles, donde la hidalguía fue bastante fuerte y las clientelas eran amplias. En el Valle de Tobalina, jurisdicción de la ciudad de Frías, estuvo fundada la Cofradía de los Doce Apóstoles, puesta bajo su advocación y la de Nuestra Señora, que integraba a los curas de las Nueve Villas de Sopellano. ${ }^{70}$ En este caso, la cofradía decayó por los serios conflictos que produjo la adscripción de los clérigos a bandos contrapuestos y, aunque se restableció en 1583, lo hizo bajo otros supuestos. ${ }^{71}$

Por los problemas derivados de este posicionamiento de algunos clérigos, en las constituciones aprobadas en el sínodo celebrado por el obispo don Pascual de Ampudia (1498) se prohibía a los clérigos beneficiados vivir con los nobles y servirles en el ejercicio de las $\operatorname{armas}^{72}$ y ser procuradores de los concejos y mayordomos de los señores, prueba de que esto era algo habitual. ${ }^{73}$

El resultado final depende de la firmeza del punto de partida y de las condiciones del desarrollo histórico de cada caso. Los valles de Valdelaguna y Valde San Vicente, con distinto grado de autonomía, se afirmaron como «villa y valle» con jurisdicción plena o parcial, mientras las villas y lugares de la merindad de Montes de Oca aprovecharon la jurisdicción de la Santa Hermandad para constituirse en la Hermandad de Montes de Oca y Valde Redoca, organismo que actuaba como una sola circunscripción frente a los poderes externos (Real Hacienda, Mesta...).

\section{BiBLIOgRAFÍA}

Alonso Martín, M. L. y Palacio Sánchez-Izquierdo, M. L. 1993. Jurisdicción, gobierno y hacienda en el señorío de abadengo castellano en el siglo XVI. Edición y estudio de las Informaciones de Carlos V de 1553. Madrid: Ed. Complutense. CSIC.

69 Cuesta Nieto 2007: 1.030-1.033.

70 Sopellano lo formaba Montejo de Cebas, Cuezva, Garoña, Santa María de Garoña, Villasemplún, Orbañanos, Tobalinilla, Barcina del Barco y Pangusión. Dato relevante es que a la comida o refresco de la cofradía los clérigos tenían prohibido llevar armas (espada, lanza, azagaya, puñal u otra cualquiera), salvo dos cuchillos para cortar en la mesa que no debían sacar contra otros «ni en burla ni en verdad» (Lobato Fraile 1995: 121).

71 ADBu, Barcina del Barco, leg. 3. Libro de la cofradía de los Doce Apóstoles (1583-1782), fols. 2-8 vo‥

72 García y García 1997: 222-223.

73 «Item, porque acaesce muchas vezes que algunos clérigos toman procuraciones por los pueblos e concejos donde viven e como los tales procuradores van a las cortes reales e a las audiencias seglares, donde reciben algunas menguas e injurias e nascen otros escándalos. Por ende, ordenamos e mandamos que de aquí adelante ningún clérigo sea osado de tomar tal procuración por concejo o comunidad e universidad seglar, ni sean mayordomos de señor alguno seglar sin licencia especial nuestra, so pena que el que lo contrario fiziere que por ese mismo caso caya e incurra en pena de un exceso por cada auto que como el tal procurador fiziere, la meytad para el que lo denunciare o provare e la otra meytad para la cárcel de Santa Pía» (García y García 1997: 239). 
Álvarez Borge, I. 1996. Poder y relaciones sociales en Castilla en la Edad Media. Los territorios entre el Arlanzón y el Duero en los siglos $X$ al XIV. Salamanca: Junta de Castilla y León.

Aranda Pérez, F. J. 2000. "El clero parroquial también se acabilda. E cabildo de párrocos y beneficiados de Toledo», en F. J. Aranda Pérez, Sociedad y élites eclesiásticas en la España moderna: 237 287. Cuenca: Universidad de Castilla-La Mancha.

Ayllón Gutiérrez, C. 2015. Iglesia rural y sociedad en la Edad Media (Alcaraz y Señorío de Villena). Madrid: Sílex.

Barreiro Mallón, B. 2008. «El asociacionismo del bajo clero: la Cofradía de Todos los Santos o Venerable Congregación del Clero de A Coruña», en S. L. Pérez López (coord.), Plenitudo Veritatis: 529 567. Santiago de Compostela: Instituto Teológico Compostelano.

Camarero Camarero, R. y Cuesta Nieto, J. A. 2017. Monterrubio de la Demanda y su iglesia parroquial. Un estudio de Historia social. Burgos, Imprenta Santos.

Casado Alonso, H. 1987. Señores, mercaderes y campesinos. La comarca de Burgos a fines de la Edad Media. Madrid: Junta de Castilla y León.

Crespo González, E. 1981. Elevación de un linaje nobiliario castellano en Ia Baja Edad Media: Los Velasco. Madrid: Universidad Complutense.

Cuesta Nieto, J. A. 2007. Sociedad y economía en la comarca de la Demanda en la Edad Moderna. Tesis doctoral inédita. Ciudad Real: Universidad de Castilla-La Mancha.

Cuesta Nieto, J. A. 2015. "La congregación de San Pedro del Valle de Monasterio de Rodilla». Boletín de la Institución Fernán González 251: 477-500.

Diago Hernando, M. 1997. «El cabildo de clérigos de Ágreda a comienzos de la Edad Moderna». Celtiberia 91: 43-68.

Díez Herrera, C. 2002. "El «valle» como unidad de organización social del espacio. Un estado de la cuestión sobre las comunidades de valle», en J. I. Iglesia Duarte (coord.), Los espacios de poder en la España medieval. XII Semana de Estudios Medievales. Nájera, 2001: 47-67. Logroño: IER.

Escalona Monge, J. 2002. Sociedad y territorio en la Alta Edad Media. La formación del Alfoz de Lara. Oxford: John and Erica Hedges Ltd.

Escrivá de Balaguer, J. M. 1988. La abadesa de Las Huelgas. Estudio teológico jurídico. Madrid: Ediciones Rialp, 3a edición.

Esteban Recio, A. 2015. "La conflictividad social en Palencia desde 1421 hasta la guerra de las Comunidades». Hispania 75 (250): $467-$ 504. https://doi.org/10.3989/hispania.2015.015

Estepa Díez, C. 2003. Las behetrías castellanas. 2 Vols. Valladolid: Junta de Castilla y León.

Franco Silva, A. 2006. Entre los reinados de Enrique IV y Carlos V. Los Condestables del linaje Velasco (1461-1559). Jaén: Universidad de Jaén.

García de Cortázar, J. A. 1996. "La organización social del espacio riojano en vísperas de la concesión del fuero de Logroño», en J. García Turza e I. Martínez Navas (coords.), Reunión científica " $E$ fuero de Logroño y su época" (1995. Logroño): 189-208. Logroño: Ayuntamiento. Reeditado en García de Cortázar, J. A. 2009. Estudios de Historia Medieval de La Rioja: 415-433. La Rioja: Universidad de La Rioja.

García y García, A. (ed. y dir.) 1997. Synodicon hispanum. VII. Burgos y Palencia. Madrid: BAC.

Goicoechea, C. 1951. «Notas para la historia de la Inquisición logroñesa: La Hermandad de San Pedro Mártir». Berceo 19: 165-174.

Herrera Mesa, P. P. 1978. "La Universidad de clérigos de Córdoba en la Baja Edad Media», en Andalucía medieval: actas del I Congreso de Historia de Andalucía, diciembre de 1976, Vol. 2: 133-146. Córdoba: Monte de Piedad y Caja de Ahorros.

Iturrate, J. 1995. "Santa Cofradía de Sacerdotes y Clérigos de Nuestra Señora de Guipuzuri». Scriptorium Victoriense 42 (1-3): 243-316.

Iturrate, J. 1997. "Cofradía de Clérigos de San Pedro Zar de Heredia». Scriptorium Victoriense 44 (3-4): 243-304.

Iturrate, J. 1998. «Cofradía de reverendos señores sacerdotes del Valle de Aramayona». Scriptorium Victoriense 45: 195-244.

Iturrate, J. 1999. "Hermandad de clérigos capellanes de Vitoria». Sancho el Sabio: Revista de cultura e investigación vasca 10: 163200.

Iturrate, J. 2000a. «Cofradía de sacerdotes en los Valles de Arraya y La Minoria en honor de la Purísima Concepción de la Virgen María». Scriptorium Victoriense 44 (1-2): 167-214.
Iturrate, J. 2000b. "Cofradía de San Nicolás de los sacerdotes de Urcabustaiz». Scriptorium Victoriense 47 (3-4): 405-435.

Iturrate, J. 2001. "Cofradía de sacerdotes de la Piedad. Zuazo de Vitoria». Scriptorium Victoriense 48 (1-4): 221-267.

Iturrate, J. 2002a. "Cofradía del Santísimo Sacramento de los presbíteros de la Climata y Sosierra de Navarra». Scriptorium Victoriense 49 (1-2): 147-239.

Iturrate, J. 2002b. «Cofradía del Santísimo Sacramento de los clérigos de Bernedo». Scriptorium Victoriense 49 (3-4): 379-436.

Iturrate, J. 2003. "Cofradía de la Asunción de Nuestra Señora de los clérigos de Markínez». Scriptorium Victoriense 50 (1-4): 327-390.

Iturrate, J. 2004. "Venerable Congregación de Sacerdotes del Señor San Pedro en el Valle de Llodio». Scriptorium Victoriense 51 (1-4): 301-334.

Lizoaín, J. M. y García, J. J. 1988. El Monasterio de las Huelgas. Historia de un señorío cisterciense burgalés (siglos XII y XIII). Salamanca: Ediciones J. M. Garrido Garrido.

Lobato Fraile, M. J. 1995. «Iglesia y sociedad en la Edad Moderna: La Merindad Menor de Castilla Vieja (Burgos)». Boletín de la Institución Fernán González 210: 111-135.

Lozano Ruiz, C. 2012. "Un mecanismo de solidaridad en la sociedad rural palentina de la Edad Moderna: las cofradías y hermandades de clérigos», en M. J. Pérez Álvarez y L. M. Rubio Pérez (eds.), Campo y campesinos en la España Moderna. Culturas políticas en el mundo hispano: CD adjunto, 1.169-1.179. León: Fundación Española de Historia Moderna.

Martín Martín, J. L. 2004. "El clero rural en la Corona de Castilla», en M. D. Martínez Sampedro y M. D. Segura del Pino (eds.), La Iglesia en el mundo medieval y Moderno: 55-82. Almería: Instituto de Estudios Almerienses.

Martín Rodríguez, J. L. 1993. "Hermandades y ligas de clérigos en los reinos hispánicos», en Cofradías, gremios y solidaridades en la Europa medieval. XIX Semana de Estudios Medievales. Estella, 20 a 24 de julio de 1992: 127-148. Navarra: Gobierno de Navarra.

Martínez Díez, G. 1982. Fueros locales en el territorio de la provincia de Burgos. Burgos: Caja de Ahorros Municipal de Burgos.

Moreno Ollero, A. 2014. Los dominios señoriales de la Casa de Velasco en la Baja Edad Media. Cádiz: el autor.

Moreno Ramírez de Arellano, A. 1992. Señorío de Cameros y Condado de Aguilar: cuatro siglos de régimen señorial en La Rioja (13661733). Logroño: Instituto de Estudios Riojanos.

Moya Valgañón, J. G. 1982. «Documentos de la Cofradía Bajomedieval de Santa María del Barrio y los Doce Apóstoles de Cellórigo». Berceo 102: 3-38.

Osorio Muñoz, M. 1984. «El bajo clero en Jaén en el tránsito a la Edad Moderna. La universidad de curas párrocos», en La sociedad medieval andaluza, grupos no privilegiasos: actas del III coloquio de Historia Medieval Andaluza: 457-474. Jaén: Diputación Provincial de Jaén.

Peterson, D. 2005. La Sierra de la Demanda en la Edad Media. El Valle de San Vicente (ss. VIII-XII). Logroño: Instituto de Estudios Riojanos.

Ruiz de la Peña Solar, J. I. 1993. "Las solidaridades vecinales en la Corona de Castilla (Siglos XII-XV)», en Cofradías, gremios y solidaridades en la Europa medieval. XIX Semana de Estudios Medievales. Estella, 20 a 24 de julio de 1992: 51-74. Navarra: Gobierno de Navarra.

Ruiz Gómez, F. 1990. Las aldeas castellanas en la Edad Media. Madrid: CSIC-Universidad de Castilla-La Mancha.

Sabe Andreu, A. M. 2000. Las cofradías de Ávila en la Edad Moderna. Ávila: Diputación Provincial de Ávila. Institución Gran Duque de Alba.

Sainz Ochoa, M. 2014. La mancomunidad hace la fuerza. La lucha señorial de las siete villas del alto Najerilla en el s. XV y su institución de autogobierno. Logroño: Instituto de Estudios Riojanos.

Vázquez Bertomeu, M. 1999. "La cofradía de los clérigos del coro de Santiago y las ordenanzas de 1457». Compostellanum: revista de la archidiócesis de Santiago de Compostela 44 (3-4): 445-493.

Vicario Santamaría, M. 1988. Censo-guía de los archivos parroquiales de la diócesis de Burgos. Burgos: Publicaciones del Arzobispado de Burgos.

Vicario Santamaría, M. 1996-2016. Catálogo de los archivos de cofradías de la diócesis de Burgos: 4 Vols. Burgos: Asociación de Archiveros de la Iglesia en España. 